\title{
Memoria, imaginación y miedo en la génesis de la diabetes mellitus. El caso de una mujer guatemalteca
}

\section{Memory, Imagination, and Fear in the Genesis of Diabetes Mellitus. The case of a Guatemalan Woman}

\author{
Jaime Tomás Page Pliego \\ https://orcid.org/0000-0003-0508-0647 \\ Universidad Nacional Autónoma de México \\ Centro de Investigaciones Multidisciplinarias sobre Chiapas y la Frontera Sur \\ jaimepagepliego@gmail.com
}

A mi hijo Sebastián, siempre presente

\section{Resumen:}

Quienes padecen diabetes mellitus frecuentemente refieren situaciones de estrés y miedo como desencadenantes de la enfermedad, y algunos también como su causa principal. Asimismo, es sabido que el sufrimiento psíquico y físico contribuye a niveles de hiperglucemia constante. Este trabajo explora las representaciones sociales sobre los recuerdos, la imaginación y el miedo por vivencias en un contexto de violencia estructural como coadyuvantes en la persistencia de sufrimiento emocional. Se expone el caso de doña Caridad, guatemalteca kiché, quien refirió haber experimentado miedo y tristeza desbordantes y constantes, agudos por lapsos, como víctima directa del exterminio étnico acaecido en su país en la década de 1980, y en 1994 durante el levantamiento zapatista en Chiapas.

Palabras clave: violencia estructural, sufrimiento emocional, etnocidio, enfermedad crónica.

\section{Abstract:}

People who suffer diabetes mellitus frequently state that stress and fear are triggers, or even the main cause, for this disease. Furthermore, it is well known that psychic and physical suffering contribute to persistent hyperglycemia. This paper explores the social representations of remembrance, imagination and fear from this experience that contribute to persistent emotional toil in a context of structural violence. These are illustrated through the case of Doña Caridad, a Guatemalan Kichean woman who recalls experiencing overwhealming and persistent fear and sadness, with acute periods, as a result of being a direct victim of the ethnic extermination that took place during the eighties in Guatemala and, later, when she experienced the 1994 Zapatist uprising in Chiapas, Mexico.

Key words: structural violence, emotional suffering, ethnocide, chronic disease. 
M

e propongo un acercamiento preliminar a las representaciones sociales sobre recuerdo, ${ }^{1}$ imaginar $^{2}$ y miedo, ${ }^{3}$ relacionadas con la persistencia por largos periodos de sufrimiento emocional ${ }^{4}$ causantes, a su vez, de estrés cíclico o persistente, el cual se expresa, entre otros aspectos, mediante alteraciones neurovegetativas. ${ }^{5}$ Dicho complejo se constituye como un factor de importancia en el desencadenamiento y agravamiento de diversas enfermedades tanto agudas como crónicas. Tal es el caso del síndrome metabólico en que el deterioro de la persona afectada tiene lugar en razón directa de la resistencia a la insulina, que se incrementa por situaciones de estrés e involucra alteraciones en el metabolismo de carbohidratos, lípidos y prótidos y da lugar a hiperglucemia (diabetes mellitus), dislipidemia (arterosclerosis, hipertensión arterial) y complicaciones frecuentes y graves como neuropatía, pie diabético, pérdida de la visión y problemas cardio y cerebrovasculares.

Las emociones como génesis o desencadenantes, desde la perspectiva de los enfermos de diabetes mellitus en México, han sido destacadas por diversos estudiosos, por mencionar: Arganis, 1998, 2005; Domínguez, 2017; Montesi, 2014, 2017a, 2017b; Lerin et al., 2015, 2017; Yáñez, 2012, 2016; Rock, 2003; NazarBeutelspacher y Zapata, 2012; Moreno, 2006; Mercado, 1996; Mercado et al., 1999; Mercado et al., 2002; Hunt et al., 1998; Eroza, 2014, 2017; Cardoso, 2006. Resalto el realizado por Laura Montesi (2018) con mujeres que atribuyen su diabetes a una vida de violencia conyugal.

Como antecedente cabe mencionar que la investigación de la que deriva este documento se centró en el estudio de población maya de los Altos de Chiapas afectada por diabetes mellitus, caracterizada por no acudir a los servicios públicos de atención médica, o hacerlo solo por emergencia. Se recurrió a sujetos preferentemente situados en los estratos sociales de población pobre, en situación de marginación social y exclusión, con servicios públicos en general de mala ca-

\footnotetext{
1 Capacidad de preservar en la memoria un acontecimiento.

2 «Reorganización y empleo constructivos [en el sentido de construir] de las experiencias perceptivas pasadas en forma de imágenes a un nivel ideativo durante una experiencia presente» (Wolman, 1984:195).

3 «Emoción intensa que implica la percepción de un peligro, agitación molesta y a menudo un deseo de escapar u ocultarse» (Wolman, 1984:309).

4 «Sensación subjetiva por parte de una persona de que su bienestar físico o mental se halla ausente o mermado, de modo que no puede desenvolverse con normalidad en la vida diaria» (Salazar y Sempere, 2012:19).

5 «El dolor emocional duele igual que el dolor físico. Esto es lo que demuestran muchas investigaciones de neuroimagen (Jaffe, 2013), que afirman que las regiones implicadas en procesamiento del dolor físico son las mismas que el dolor emocional y la angustia social» (Corbin, s/f).
} 
lidad o inexistentes, particularmente de atención médica y educativa. Conjuntos sociales afectados por alguna forma de violencia estructural, un mayor riesgo de padecer enfermedades, en general, y con un elevado índice de mortalidad.

La investigación se dirigió a personas con diabetes que no asisten regularmente a los servicios sanitarios puesto que se trata de la población sobre la que hay menos estudios, aun cuando representan la mayoría. Los estudios sobre diabetes mellitus se han concentrado en aquellos que se atienden con regularidad en centros hospitalarios o clínicas (Trujillo et al., 2008; Nazar-Beutelspacher y Salvatierra, 2010; Acero, 2012, 2019; Yáñez, 2012, 2016).

Cabe mencionar además que las estadísticas con respecto a las complicaciones y la mortalidad asociadas con la diabetes se construyen con base en los estratos de población que acceden a los servicios públicos de salud, y no ofrecen información útil referente al sector de nuestro interés.

\section{Método}

Los sujetos que se prestaron a participar en la investigación no constan en registro institucional alguno como diabéticos. Para captarlos fue necesario recurrir a diferentes mecanismos. En Tenejapa la investigación se promovió mediante la radio local y de ese modo llegaron varias personas dispuestas a colaborar; además, se levantó una encuesta en el centro del poblado a partir de la cual se detectaron algunos de los sujetos. En todos los casos fue importante "el gancho" de la glucometría, ya que motivó el acercamiento voluntario de personas que se sospechaban enfermas y que en algunos casos decidieron participar en el estudio. En Chamula y San Cristóbal la selección se llevó a cabo con base en redes de conocidos y colegas establecidas durante años de trabajo de campo.

Se realizaron 52 entrevistas: 22 en Chamula, 14 en San Cristóbal de Las Casas y 16 en Tenejapa; de estas, 38 se efectuaron en dos o tres sesiones, todas registradas en audio y algunas en audio y video. A partir de los datos recabados en la entrevista inicial se seleccionó a 14 personas con el propósito de realizar un seguimiento durante dos años o mientras sobrevivieron, en relación con el manejo de la diabetes y con pormenores de su vida cotidiana. Doña Caridad quedó en dicho conjunto. ${ }^{6}$

6 El caso de doña Caridad utilizado en el presente artículo fue retomado y editado del libro de Page, Eroza y Acero (2018) Vivir sufriendo de azúcar. Representaciones sociales sobre la diabetes mellitus en tres localidades de los Altos de Chiapas, del CIMSUR-UNAM, como referente respecto de emociones, temática no contemplada en el libro referido. 
Durante el seguimiento se realizaron visitas intermitentes (un día por semana, en ocasiones hasta dos, dependiendo de los pormenores). Los criterios de selección fueron: la disposición y el interés por colaborar y que fueran casos paradigmáticos: por un lado, con control bajo o nulo sobre la enfermedad, tanto de orden terapéutico (fármacos o plantas), como dietético, así como adicciones a refresco y/o cerveza; por otro, que la atribución de la enfermedad fuera variable, es decir, no necesariamente centrada en criterios biomédicos.

Las visitas transcurrieron en el domicilio de los enfermos. En cada ocasión se practicó una glucometría, cuyo resultado se comentó con el enfermo y sus familiares. Luego "platicamos" sobre los eventos significativos de la semana, tanto en relación con la enfermedad como con los problemas colaterales y posibles soluciones, la mayoría de las veces a solicitud del enfermo o los familiares. En algunos casos asistí, en calidad de observador, a la visita con algún terapeuta no biomédico, o cuando se presentó alguna circunstancia crítica en el seno familiar. Además, dado que soy antropólogo y médico, inevitablemente, cuando se me solicitó, ofrecí orientación a los enfermos y la familia.

En torno a los aspectos éticos, se contó con el «consentimiento informado» de todos los entrevistados, explícito en los audios. Algunos pidieron que se utilizara algún alias. Ese fue el caso de doña Caridad.

\section{Generalidades teóricas del proyecto}

Cabe aclarar que si bien la teoría de las representaciones sociales opera como marco general del proyecto de investigación, para este trabajo los aspectos teóricos, además de lo que se expresa en los siguientes párrafos, se centra en categorías y nociones específicamente aplicables a las emociones.

El marco que dio coherencia a la investigación se centró en el estudio de las tres esferas que Denise Jodelet (2008) propuso en torno a las representaciones sociales: subjetiva, intersubjetiva y transubjetiva.

\footnotetext{
7 Glucometría: medición de la glucemia mediante una gota de sangre obtenida ambulatoriamente, que se deposita en un reactivo que es registrado e interpretado por un aparato manual denominado glucómetro.

8 El hecho de ser médico no sesgó la interacción con la familia, dado que desde el principio a todos los colaboradores les quedó clara mi postura abierta hacia cualquier otro tipo de terapéutica que fuera percibida como efectiva.
} 
La esfera de la subjetividad remite a la apropiación/encarnación y elaboración de la experiencia del individuo fundada en procesos cognitivos, emocionales y físicos entre los que se enfatiza, además de la palabra, la acción no verbalizada como medio de transmisión de conocimientos (Ortner, 2006, citado en GoodEshelman, 2015:145; Le Breton, 2012; Csordas, 1993) por medio de los cuales se configuran/asimilan/transforman las representaciones de todo orden.

La subjetividad está histórica y socioculturalmente determinada. Lo sociohistórico, según Castoriadis (1997:3), «constituye la condición esencial de la existencia del pensamiento y la reflexión», cuyo contenido intrínseco y estructurado reside en la esfera transubjetiva.

La esfera de la subjetividad (Jodelet, 2008:51-52) brinda elementos para comprender las formas en que las personas concebimos y vivimos el proceso de salud-enfermedad-atención-prevención; para percibir y comprender cómo piensan y lo que expresan los coterráneos, las particularidades del sufrimiento generado por la enfermedad (padecer) y por otras causas.

Así como la subjetividad —el pensamiento-, las emociones están culturalmente definidas. Rosaldo (1984:137) sostiene que el pensamiento no existe al margen de lo emocional, y que las emociones no se suscitan de forma aislada, sino fusionadas al pensamiento. En tal sentido, podría arriesgarme a decir que subjetividad sería a la vez pensamiento y emoción, ambas producto de una construcción social y cultural (Le Breton, 2012:69; Rosaldo, 1984:138-139), en el entendido de que a toda emoción subyace una representación sobre esta, así como las formas y los momentos de su expresión.

La subjetividad, que va de la mano de la intersubjetividad, es el intercambio comunicativo entre personas que se expresa dentro de un "patrón colectivo susceptible de ser reconocido por los pares» cuyos «matices de la particularidad individual [son] siempre el producto de un entorno humano dado y de un universo social caracterizado de sentido y de valores» (Le Breton, 2012:67-68).

Cuando se expresan abiertamente los sentimientos y las emociones o se pretende enmascararlas o fingirlas según los intereses particulares del intercambio, el observador ha de poner atención además de los mensajes verbales o los silencios, en las expresiones faciales y corporales (embodiment) (Csordas, 1993 y Le Breton, 1999).

La importancia de la esfera de la transubjetividad estriba en que configura la intersubjetividad y la subjetividad en un proceso de retroalimentación de esferas en las que se inmiscuye y que a la vez reestructura. 
En la formación de las representaciones sociales, la esfera de la transubjetividad se sitúa en relación con la intersubjetividad y con la subjetividad, y remite a todo lo que es común para los miembros de un mismo colectivo [...]. Su escala abarca tanto a los individuos y a los grupos, como a los contextos de interacción, las producciones discursivas y los intercambios verbales (Jodelet, 2008:53).

Por otro lado, Castoriadis señala:

Los individuos socializados son fragmentos hablantes y caminantes de una sociedad dada; y son fragmentos totales; es decir, que encarnan -en parte efectivamente, en parte potencialmente- el núcleo esencial de las instituciones y de las significaciones de su sociedad. No hay oposición entre el individuo y la sociedad, el individuo es una creación social, a la vez en tanto tal y en su forma histórica cada vez (Castoriadis, 1997:3-4).

No es mi intención profundizar en esos aspectos, toda vez que pretendo más bien introducirme en el sufrimiento emocional bajo las nociones ya enunciadas. Sin embargo, en términos de relación entre representaciones sociales y emociones, considero que es en la interacción social, en la experiencia intersubjetiva, donde se configuran las representaciones sociales sobre ciertas emociones y se van conformando, así como las formas de su expresión o represión de acuerdo con las circunstancias, es decir, los espacios socialmente adecuados y las condiciones de su expresión (entendiendo que no toda emoción se produce y/o manifiesta como resultado de las representaciones sociales, por ejemplo, las emociones que produce el vértigo).

De tal manera se precisa, según el contexto, dilucidar los condicionamientos subjetivamente interiorizados en cuanto a ver/percibir/bloquear las emociones. $Y$ respecto del sufrimiento emocional, expresarlo ya sea ampliamente, con restricciones o reprimirlo. Asimismo, se estructuran barreras protectoras o aperturas frente a los sentimientos de los otros. Para el rejuego del «sufrimiento emocional persistente» son esenciales los recuerdos y el acicate de la imaginación. Y dentro de esto, en su caso, el miedo.

\section{Sufrimiento emocional, recuerdo, imaginar y miedo}

Catherine Lutz (1998) sostiene que lo sociocultural (y por lo tanto las representaciones sociales) determina la manera en que concebimos y experimentamos las 
emociones y cómo las manifestamos, y que estas juegan un papel primordial en las emociones intersubjetivas. Al respecto señala:

Although we may experience emotion as something that rises and falls within the boundaries of our bodies, the decidedly social origins of our understandings of self, the other, the world, and experience draw our attention to the interpersonal processes by which something called emotion or some things like joy, anger, or fear come to be ascribed to an experienced by us (Lutz, 1998:138-144). ${ }^{9}$

Si bien la expresión de las emociones cumple un papel en los intercambios intersubjetivos, esta se da también en la soledad, en el sufrimiento, el enojo o la alegría interiorizados o silenciados que pueden inferirse a partir de gestos, expresiones gestuales o posturas corporales, sin que el sujeto afectado intente alguna interacción; es el caso del sufrimiento emocional, que remite a un ámbito extenso, y al que busco acceder en este trabajo desde el plano de lo subjetivo, de lo personal, reflexionando sobre el recuerdo, la imaginación y el miedo como elementos que apuntalan su presencia y persistencia, y que en el caso de doña Caridad, a la par del desapego al tratamiento médico (dieta-medicina-ejercicio), influyó para elevar los niveles de glucosa en sangre, el deterioro corporal y eventualmente a la muerte.

\section{Sufrimiento emocional}

Salazar y Sempere (2012) y Sirito et al. (2014) definen sufrimiento emocional como "sufrimiento" y "malestar". Para nuestro caso, tiene como sustratos la memoria, la imaginación y el miedo. Aquí lo distingo del sufrimiento social (Das et al., 2001).

Kleinman y Kleinman (1991:280) definen sufrimiento como un aspecto universal propio de la experiencia humana, en el que individuos y grupos padecen y soportan cierto tipo de agobios, problemas, lesiones corporales y emocionales.

Asimismo, Farmer (2004), Kleinman (1998) y Bakan (1979) señalan las enormes variaciones subjetivas a que está sujeto el sufrimiento, así como los innumerables

\footnotetext{
9 Aunque podemos interpretar una emoción como algo que nos sube y nos baja por dentro, los orígenes decididamente sociales de nuestra forma de entendernos a nosotros mismos, a los demás, al mundo y la experiencia mueven nuestra atención hacia los procesos interpersonales por los cuales algo llamado emoción o cosas como alegría, enojo o miedo se atribuyen a algo que hemos vivido.
} 
motivos a que da lugar, que van desde el dolor por una herida, un golpe o una infección, el "sufrimiento" efecto de una enfermedad que no cursa con dolor físico, pero que merma las capacidades del individuo e incluso lo lleva al deterioro de sus facultades; el que deriva de una pérdida personal por un mal de amores o por la defunción de un ser querido que a su vez variará dependiendo de la cercanía; la angustia y pena por hambre, por falta de trabajo, etcétera.

Kleinman y Kleinman (1991: 275-278) afirman que el sufrimiento apuntala la experiencia que se constituye como medio intersubjetivo de transacción social; que es resultado de categorías culturales y estructuras sociales que interaccionan en los procesos psicosociales de una realidad particular. Señalan que, en términos de Bourdieu (2005), constituyen una de las diferentes matrices sociales a partir de las cuales se estructuran los habitus.

Por tanto, el sufrimiento en tanto experiencia corta el flujo y los planes de vida, reconfigura las representaciones sobre lo peligroso y ayuda a perfilar las expresiones personales ante los diferentes estímulos (Kleinman y Kleinman, 1991:278).

Kleinman (1988:48) opina que las narrativas del padecer son historias que elaboran los enfermos. El esquema del discurso, las metáforas y los recursos retóricos estructuran dicha narrativa acomodando las experiencias a modo de comunicar y realzar con efectividad lo que se pretende transmitir; narrativa que a la vez contribuye a reestructurar y dar orden a su propio sufrimiento. Para el caso de doña Caridad, es a partir de su relato sobre la experiencia del exterminio guatemalteco y del padecer "azúcar" que podemos extraer y significar el sufrimiento emocional que marcó su vida. Contó desde su particular forma de ver y vivir el mundo los pormenores que más significativamente le afectaron, dejando entrever los diferentes intersticios y las causas de algunos de sus sufrimientos enmarcados en la memoria personal y la imaginación.

\section{Memoria y recuerdo}

Como señala Bustamante (2019:8), «toda memoria individual está inevitablemente enmarcada en un marco social» porque «ante todo la memoria es una construcción intersubjetiva enraizada siempre en la acción. [...] la memoria no como 'algo dado' sino como 'algo construido y por construir' inexistente al margen de la acción». 
En este orden, el recuerdo de eventos y acciones en los que el sujeto ha participado se constituyen como el sustrato a partir del cual la persona va construyendo la memoria y la conciencia:

Uno no "es quien es" porque "le pasó eso" sino porque ha registrado y ha entendido lo que le pasó de una determinada manera, seleccionando, remendando y emparchando huellas de experiencias personales con relatos ajenos. La memoria no sería un archivo de documentos sino una construcción enriquecida por la imaginación (Braunstein, 2008:8-9).

Asimismo, la memoria es discontinua, «es una 'memoria involuntaria' de la que la mayor parte de sus elementos se sitúan en el inconsciente, son muy difíciles o imposibles de recordar. La memoria está desgarrada por lo imposible de recordar, por lo que fue consciente y sabido en su momento, pero no pudo ser asimilado por el sujeto y quedó separado de la urdimbre, del tejido (texto) de sus evocaciones» (Braunstein, 2008:13). El aparente olvido ayuda a resaltar aquellos elementos que prevalecen. Entonces, el recuerdo es la «capacidad de conservar la conciencia de algo que fue y ya no es [...] como afirmación de un cierto saber sobre algo vivido, visto u oído en el pasado» (Braunstein, 2008:16). De los recuerdos que prevalecen, predominan los que son resultado de experiencias dolorosas, vergonzosas y momentos "felices" que, aunque tienden a diluirse, nunca dejan de ser accesibles. Pero hay ciertos eventos, en este tenor, que, ante las circunstancias de vida, son los elementos a partir de los cuales se reconfigura la identidad, los que justifican los cambios cuando una persona se transforma de cierto modo en otra, como en el caso de doña Caridad, quien a partir de la vivencia del exterminio y luego del exilio experimentó un sentido diferente de su vida y de su sufrimiento emocional.

Wolman (1984: 285) explica el recuerdo como la «repetición de la incorporación en la memoria de materiales previamente aprendidos» que, asumo, lleva no solo a la recreación de las imágenes de situaciones pasadas sino que, en el caso del sufrimiento, amenaza con reproducir las mismas manifestaciones neurofisiológicas que tuvieron lugar en el evento de origen, tal vez con diferente intensidad, y que aun con el paso del tiempo, en el procesamiento psíquico de la experiencia puedan diluirse hasta desaparecer: angustia, tristeza, desolación, soledad, abandono, desesperanza, esperanza, incluso alegría, etcétera, presentes en las diferentes situaciones. En consonancia, ambas manifestaciones y emociones operan en un círculo interdependiente, en el que cada una producirá efectos en la otra. 


\section{Imaginación}

Entiendo la noción de imaginar como «Reorganización y empleo constructivos [en sentido creativo] de las experiencias perceptivas pasadas en forma de imágenes a un nivel ideativo durante una experiencia presente» (Wolman, 1984:195) y de manera prospectiva. Al respecto, el Diccionario de la lengua española la define como la "facilidad para formar nuevas ideas» (DRAE, s./f). Tiene como sustrato el recuerdo, lo posible, según los contextos, o lo imposible, el fantaseo. En el caso que nos ocupa, imaginar remite entre otras cosas al fantaseo, o como se denomina en lenguaje coloquial, a «soñar despierto», o el «si hubiera» como algo que tiene una posibilidad remota o ninguna de suceder y cuyo resultado, en el sentido de la díada sensaciones-emociones, ayuda, por ejemplo, en los casos de pérdida reciente de un ser querido. El recuerdo es al pasado lo que la imaginación a un futuro probable (Thomas, 2019).

\section{Miedo}

Respecto del miedo, este ciertamente acontece de manera limitada en la vida de todos; los acontecimientos que lo generan producen una reacción que marca la memoria de manera indeleble. Wolman lo define como una «emoción intensa que implica la percepción de un peligro, agitación molesta y a menudo un deseo de escapar u ocultarse. El miedo se acompaña de cambios fisiológicos, principalmente del sistema nervioso simpático» (Wolman, 1984:309). Su presencia en los testimonios que obtuvimos derivó de accidentes fatales o de actos de violencia estructural explícita: persecución política, exterminio de poblaciones, asaltos, o la que se manifiesta en el hogar, que es constante y sistemática.

El miedo genera respuestas que varían desde una angustia moderada hasta una reacción neurofisiológica y emocional extrema; el sustrato es una descarga descomunal de adrenalina o norepinefrina ${ }^{10}$ y puede ocasionar que los individuos se paralicen, se orinen, defequen o se desmayen; o bien, como en el caso de doña Caridad y sus allegados, que al verse expuestos a una campaña de exterminio de población originaria encabezada por el Estado guatemalteco intenten huir, como fue su caso, o respondan con violencia, como lo hizo la guerrilla. Todo

10 La noradrenalina es una catecolamina con múltiples funciones fisiológicas y homeostáticas que puede actuar como hormona y como neurotransmisor. Las áreas del cuerpo que producen o se ven afectadas por la norepinefrina son descritas como noradrenérgicas (Pérez, s./f). 
lo que tiene que ver con el tipo de reacciones que se originen a partir de esta noción dependerá no solo del carácter de cada persona o líder del grupo y de lo que en el momento provoque el miedo, sino de las condiciones materiales e ideológicas que prevalezcan entonces.

El sufrimiento persistente que se genera a partir de experiencias aterradoras ha sido etiquetado por la biomedicina como «trastorno de estrés postraumático» (TEPT) que, al decir de Kleinman y Kleinman (1991:291), tiende a invalidar el significado moral y político del sufrimiento al pretender significarlo como una entidad curable. Así, el síndrome desde esta perspectiva puede caracterizarse por los siguientes síntomas: reviviscencias, pesadillas, angustia grave y pensamientos incontrolables sobre el evento que se agrupan en cuatro tipos: recuerdos intrusivos, evasión, cambios negativos en el pensamiento y en el estado de ánimo y cambios en las reacciones emocionales y físicas. Los síntomas pueden variar con el tiempo o de una persona a otra (Mayo Clinic, 2019).

\section{La guerra en Huehuetenango}

Si bien el Ejército Guerrillero de los Pobres (EGP) se fundó en 1972, como narra Kobrak (2003), no realizó sus primeras incursiones en Huehuetenango hasta 1978. Una buena parte de la población ya estaba dispuesta a incorporarse a sus filas. Sin embargo, debido a la falta de armamento, no inició la acción guerrillera hasta el 24 de agosto de 1980, cuando se lanzó a conquistar los pertrechos de que disponía el destacamento de la Guardia de Hacienda asentado en Huehuetenango. Señala dicho autor:

La estrategia de la guerrilla ya no era pasar desapercibida sino anunciarse como una opción frente al gobierno. [...]. El EGP no mantenía en secreto su apoyo entre los campesinos. Publicaba en sus comunicados internacionales listas de las comunidades donde había hecho mítines y organizado a la población (Kobrak, 2003: 32).

Lo anterior dejó al descubierto las bases de apoyo. En respuesta, el ejército guatemalteco se enfiló al exterminio de la población local: «solo en Huehuetenango más de 10000 personas fueron asesinadas y muchas más huyeron de sus comunidades. En la disputa entre la guerrilla y el gobierno los huehuetecos pusieron las víctimas» (Kobrak, 2003:9). El proceso de guerra tuvo lugar durante los regímenes 
militares presidenciales de los generales Romeo Lucas García y Efraín Ríos Montt (Arias, 1983:57-58; Kobrak, 2003:9).

En ese contexto, el 25 de diciembre de 1981 el ejército guatemalteco arrasó la aldea de Nebaj en el Kiché guatemalteco, donde tenía su hogar doña Caridad. En esa coyuntura se conjugaron de manera ostensible la violencia, la migración forzada y, derivado de ello, emociones extremas y sufrimiento emocional persistentes entre los lugareños. Tales aspectos de alguna manera abrieron el camino para el acercamiento que propusimos en este trabajo.

\section{Doña Caridad}

Doña Caridad nació en 1950, en Nebaj. Además del idioma kiché, hablaba ixil y español. Católica y analfabeta, vestía ropa occidental. Es un dato que llama la atención, dado que por lo general sus coterráneas utilizan indumentaria típica. Si bien transitó repetidas veces entre México y Guatemala, los últimos años de su vida los pasó en San Cristóbal de Las Casas. Nuestro primer contacto sucedió el 20 de abril de 2009, cuando ella tenía 58 años. Falleció en enero de 2010, a los 59.

En su relato, doña Caridad puntualizó que su sufrimiento emocional inició en 1976, debido a que, después de haber contraído sarampión, su esposo y cuatro de sus cinco hijos murieron por complicaciones de la enfermedad. Fue un proceso complejo y desgastante. Y cinco años después su aldea fue arrasada por los kaibiles. ${ }^{11}$ Ella y algunos de sus familiares lograron escapar del exterminio gracias a que se refugiaron en las montañas que, a la sazón, estaban bajo control de la guerrilla. Los agresores quemaron casi todas las casas de la aldea, incluyendo pertenencias y el fruto de la cosecha más reciente:

y como en la aldea así estamos abiertos de este y de este y de este lado, el ejército se dejó venir de Huehuetenango, aparte todos los que se vienen de Luguaj. Habíamos hecho tamales del 25 de diciembre. Terminamos de comer cuando escuchamos. ¡Ay Dios mío! Y en eso empezaron a quemar las casas. Nosotros ya subimos encima de los cerros. Hay muchachos que son fuertes, vienen a vigilar qué están haciendo los soldados. Ya terminaron las casas. Llegaron como a las nueve de la mañana, a las doce, a la una, ya se oscureció el sol por el humo de las casas. No hay nubes, pero por el humo. Ya como si ya se oscureció. Y ya estábamos en el monte, así, sin comer, nada más con

11 Kaibiles: fuerzas especiales del ejército guatemalteco, que entre 1982-1983 ejecutaron acciones de exterminio en contra de la población maya de Guatemala. 
la ropa así nos quedamos. Y no se puede poner fuego porque lo miran el fuego de noche, nomás estamos en el monte, con hambre, con sed. Ya está tapiscado todo el maíz, ya está guardado el maíz, el frijol, los chilacayotes, haba... Se acabó todo y hasta el año se da la cosecha.

El hermano de doña Caridad propuso al grupo familiar refugiarse en Motozintla, Chiapas, lugar donde él había vivido y trabajado. Decía: «De quedarnos no nos vamos a morir por la guerra, nos vamos a morir por hambre». Un primer grupo, en el que iban los padres de doña Caridad y el hijo de 11 años, tomaron la delantera, debido a que ella quiso recoger ropa que tenía escondida.

Bajamos a las 6 de la mañana. En el cerro hay una piedra, ahí nos sentamos con mis papás y les dije:

- Miren ustedes, papás, voy a pasar a traer mi ropa, se van ustedes aquí derecho en el camino. Y se fueron, pues, por el miedo y porque ya no hay comida. Y cuando salimos, pues.

—Te vas con tu abuelita, con tu abuelito —le dije, pues, a mi hijo. Él se me quedó viendo y me dijo:

— ¿Por qué no quieres, pues, que me voy contigo? Lo vi sus ojitos y me quedó viendo, y le dije que no quiero que se canse él:

- Te vas a ir con papá y mamá, yo me voy a ir a traer la ropa que hemos dejado guardada — - dije, pues, a mi hijo.

— ¡Bueno! —dice. Pero se me quedó viendo.

En el traslado a Huehuetenango, doña Caridad se percató con horror de la gran masacre que los kaibiles perpetraron en otras aldeas a lo largo de esos días: "Mientras nosotros andábamos veíamos que las gentes estaban cortadas su cuello, escuchamos que ahí en el Madelo, por donde pasamos, a la gente la secuestraban, los tiraban en el río, muchas cosas. A los niños, a las señoras los dejan tirados ahí».

Después de once días de deambular, la mañana del 6 de enero de 1982 doña Caridad y familiares que la acompañaban llegaron a Huehuetenango. Se enteraron de que el ejército había apresado a sus padres y a su hijo. Nunca más supieron de ellos.

Mi papá llegó en Huehue con mi mamá. Dice:

- Vamos a comprar un poco de comida, ya tiene cinco días que no hemos comido. 
-Me voy con ustedes —les dijo mi hijo.

$Y$ ya no regresaron, fueron a comprar en el mercado de Huehue, y las otras hermanas se quedaron ahí donde paran las camionetas que se vienen para acá. Llegamos ahí donde estaban mis hermanas:

- ¿Y mis papás?

- Se fueron a comprar.

Ahí ya no regresaron. Yo sentí que de una vez me enfrié, que ya no están. Ahí corriendo me fui a buscarlos en los mercados, en las farmacias, qué tal que se enfermaron y fueron a comprar medecina, o dónde están. Y ya no los encontramos. Nadie nos dio razón. Ya no llegaron ellos. Tenía yo mucho espanto, mucho miedo, mucha hambre. Tal vez de ahí viene mi azúcar.

Amaneció otra vez, y ya no los encontramos. De una vez se quedaron secuestrados los tres. Y como ahí estaban mis hermanas, mi hermano que es maestro, y como había estudiado en México, al final para allá nos fuimos.

A los dos días llegamos a Motozintla. Llegamos con las madres. Un día estuvimos ahí en Motozintla. Después nos mandaron a un lugar más para acá en Comalapa, ahí en las montañas. Ahí nos mandaron a cortar café.

No sabemos cortar café. No sabemos corte, nada. El trabajo ahí en la aldea trabajamos con azadón, con machete, con hacha, pero ya cortar café no sabemos. Pero nos mandaron a cortar café, pero no con gusto. Nos morimos de tristeza. No comemos nada. Y ya estamos en otro país y ya no está completa la familia, y eso nos afectó un chingo. Sí. Estuvimos ahí, ya después salió la luna [pasaron los días] y no tenemos casa. Llegamos con la gente, pero la gente está acostumbrada con su comida y llegamos de a montón, y así entró problema. Y vino la madre a ver si tenemos oficio.

Y entonces pagamos una casa y ahí nos pusimos a trabajar tejiendo, y cada semana se va una de las señoras que están con nosotros a vender nuestros tejidos, a veces en la capital de México.

Y como también muy poco español sabemos, no muy sabemos, puro en idioma hablamos solo los dos idiomas manejamos bien: el ixil, pero el español lo manejamos poco. Cuando nos vamos a pueblo de Nebaj, puro ixil, venden ahí, en sus idiomas hablamos, y ya en nuestra casa hablamos en nuestro idioma, el español sí poco sabemos.

En Motozintla estuvimos. Un año estuvimos ahí. Pero ya llegó más gente ahí en Motozintla, y mi hermano como es maestro encontró un su trabajo en México y se fue y le fueron a mostrar su trabajo ahí en Toluca y nos fuimos con él.

Siete años vivió doña Caridad entre Toluca y la Ciudad de México. En 1992 regresó a Guatemala con la ilusión de encontrar a su hijo. Ahí residió por poco tiempo, para luego volver a México, donde se embarazó y tuvo un hijo, como 
madre soltera, que la acompañó hasta el final de sus días. En ese tiempo doña Caridad desarrolló destrezas en el comercio y eso le permitió cierta solvencia en el exilio.

En 1993, gracias al éxito de sus transacciones como comerciante, doña Caridad pudo reunir los medios para comprar un terreno y construir una casa a fin de establecerse en San Cristóbal de Las Casas, Chiapas, más cerca de su familia. Y una vez que estuvo lista su nueva morada, organizó la mudanza de sus pertenencias: «Como yo no muy me hallo allí [Toluca], estoy pensado para acá, porque mi hijo, nunca se me olvida mi hijo, mis papás, los tres importantes en mi corazón (...). Y me vine aquí y sí me gustó el lugar, que está cerca de Guatemala».

El 1 de enero de 1994 el Ejército Zapatista de Liberación Nacional (EZLN), integrado principalmente por mayas chiapanecos, declaró la guerra al gobierno mexicano mediante la Declaración de la Selva Lacandona, que demandaba: «trabajo, tierra, techo, alimentación, salud, educación, independencia, libertad, democracia, justicia y paz» (Comandancia General EZLN, 1994). El levantamiento sembró esperanza entre algunos de los habitantes del estado de Chiapas y del país, y en otros indignación o miedo. Durante los primeros 10 días la zozobra imperó entre la población y al transcurrir los primeros meses del año se movilizó un sector entusiasmado de la sociedad civil, para luego apagarse como lo hace un cerillo.

En los primeros días de ese año doña Caridad, aún en Toluca, recibió un mensaje de una persona conocida de San Cristóbal. Le avisaba que habían entrado a robar en su casa y que se llevaron todas sus cosas, y que se sospechaba de «los alzados» (el EZLN). Ese hecho le causó una fuerte crisis emocional que aún recuerda con dolor, evidente en su expresión facial y en sus ojos humedecidos, debido a que además de la pérdida de sus pertenencias, le abrió viejas heridas: miedo, angustia, zozobra vividas en Guatemala en 1982.

¡Ay Dios mío!, dije yo cuando escuchamos que entraron los zapatistas en las casas. ¿Y mis cosas? Pues las sacaron. Pero pensé que ya no tenía yo nada. A los tres días ya estaba yo que me moría de sed, me bajé en la noche a tomar agua, mucha agua. Y ahí

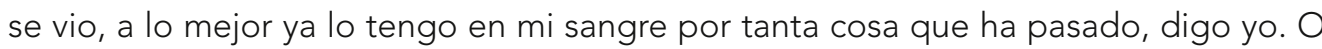
en ese momento me dio [el azúcar], quién sabe.

En 2002 doña Caridad realizó una estancia en Guatemala, de ese tiempo narró una experiencia que a ella le resultaba de mayor importancia para explicar el agravamiento de la diabetes. Con lágrimas en los ojos y la voz quebrada narró: 
Un día me senté pensando así: "Con un cántaro como ese mi hijo iba a acarrear su agua". Y me senté solita, así (sentada en una pequeña silla con los codos apoyados sobre las rodillas y el mentón sobre la palma de las manos) y me quedé viendo el cántaro. "Dios, qué dichoso el cántaro cuando estaba en su espalda de mi hijo" -pensé yo. Me dio una alegría aquí en mi sangre. Y una alegría sentí en ese momento. Y después, me puse a pensar: "¡Está vivo mi hijo! ¿Por qué me dio una alegría?". Por lo que decidí ir a ver a unos señores que adivinan para preguntar por él.

En Escuintla, Guatemala, había unos señores que saben adivinar, que saben de muchas cosas. Estaban ahí en un patio. Fui con ellos, pero ahí sí me jodieron esas gentes porque yo cuando fui, tengo la diabetes, pero estoy fuerte, tengo mucha fuerza, viajaba yo, negociaba yo. Llegué con uno que se llama Felipe, y me dijo: -No te preocupes, tu hijo se huyó cuando lo vio que sus abuelos los agarraron, él se echó a correr, se fue, ahora está en Tijuana, estudió, ya sabe leer, ya sabe escribir, ya tiene familia —-me dijeron-, pero en Tijuana. Si quieres te doy la dirección, pero me das 1500 quetzales $^{12}$ ahorita.

Regresé en mi casa, y como allá tengo dinero, porque viajaba yo, vendía yo, no como aquí, que ya no aguanto. Y fui y le entregué. Me dieron una dirección: —Ahí te vienes de aquí en ocho días, te vienes y te damos la foto de tu hijo, porque si te vas a ir buscar ya no lo vas a reconocer porque él ya es un señor. Pero te vamos a dar la foto, y si te vas a ir buscarlo, lo vas a reconocer por la foto.

Regresé otra vez, pero de aquí a ocho días regresé otra vez. Ya es otro el que está, un gordo y platiqué entonces: - Me das otros 1500 . Ya el otro señor ya no me dijo nada. Y después cuando salimos, terminé pues. Le dejé el dinero, me dio una hoja de papel en blanco: - Cuando lo vas a ver ahí va a aparecer tu hijo.

Ya me fui, y salí junto con ese señor e hizo así (mostró que le pasó la mano cerca del hombro izquierdo, por detrás de ella, como si estuviera barriendo), no me tocó, nomás pasó tres veces. De momento cuando ya estoy en la esquina de la otra cuadra ya siento que me muero que se para mi corazón. Y cuando lo sentí, mi fuerza la quitó el señor. Mi fuerza, siento yo que puedo hacer muchas cosas, pero en ese momento me la quitó ese señor.

Si no hubiera ido con ellos, yo voy a pasar a buscar mi hijo dónde está. Pero ya cuando me hicieron así ya no. Hasta la fecha hoy ya no puedo, ya no regresa mi fuerza. Sí, tengo diabetes, pero tengo mucha fuerza. Comía bien, viajaba yo, pero me quitó la fuerza. Pero no me tocó, nomás que me pasó así cerca de mi hombro. De momento ya me quedé sin nada, se fue mi dinero, se fue todo. No tengo cantidad de dinero, pero sí tengo bastante para comer, y ahora, nada (doña Caridad, entrevista, 2002).

\footnotetext{
12 Aproximadamente $\$ 1553.00$ pesos mexicanos al tipo de cambio de 2002.
} 
Posterior a esa experiencia, además de la pérdida de fuerza, doña Caridad señaló con muestras de tristeza que su agudeza visual fue gradualmente disminuyendo. En la primera entrevista refirió que ya casi no veía: «Ahora ya me estoy mejorando de mis ojos. Sí, pero he pasado, como dicen, de unos miedos muy fuertes». Al expresar lo anterior cruzó los brazos y los apretó contra su cuerpo.

Con objeto de completar la breve imagen que se delinea sobre doña Caridad, cabe hacer mención del irregular manejo que realizó en torno a su problema de "azúcar", lo primero que señaló en 2010, durante la primera entrevista, fue:

Yo, pues, no me estoy tomando medicina ${ }^{13}$ de la diabetes, porque me hace mucho daño. Me arde mucho la boca del estómago cuando tomo la medicina de la diabetes. Y más sudo y ya no como y me da un disgusto. Ya tengo tres años que no tomo medicina. Nomás azúcar no como. Mi café. El café sí no lo voy a dejar, pero sin azúcar el café, así, amargo. Plantas no, no he tomado. Pero sí, hace poco que pasó un señor vendiendo un líquido. ${ }^{14}$ Viene de lejos, para la diabetes, dice. Ese lo compré, lo estoy tomando ahorita, todavía lo tengo.

Relató que fue en Toluca, después del levantamiento del EZLN, que se percató de la enfermedad. Su hermana la llevó a un Centro Naturista "Shaya Michán" donde le recetaron frutas y unas yerbas de las que no recordó el nombre. "Compré las frutas: manzana, papaya y mango; me recetó, el salvado, germen de trigo y salvado de trigo. Ese es el que me recetó. Y ya la comida, unas dos tortillas de esas grandotas, ni un pan. Me recetó la levadura de cerveza y empecé a comerme eso durante un mes». Al terminar el tratamiento tenía que regresar a consulta, pero debido al elevado costo de la consulta no asistió.

Al poco tiempo viajó a la ciudad de Guatemala donde una conocida la llevó con un médico que le recetó insulina, misma que se aplicó, hasta que, a los ocho meses, en Toluca, un homeópata le retiró la hormona y le prescribió unos "chochitos", que suspendió al término del contenido del frasco, todo ello sin conocimiento del estado de su glucemia.

Ya seis meses antes de su defunción, el 8 de junio 2009, en San Cristóbal, constaté el color verdoso de su piel; sin embargo, ella refirió que aunque había bajado de peso se sentía bien. Comentó que, dado que la homeopatía le había

\footnotetext{
13 Glibenclamida de 5 mg y Metformina de 850 mg.

14 Vino Tónico Nueva vida. Contenido: boldo, zarzaparrilla, quina, nuez moscada, azafrán, china, guacaya, nogal geciana, hígado carificara, citrato fólmico, ácido fólico, vitaminas b12 y b1 y vino jerez (información transcrita de la etiqueta del frasco).
} 
caído bien, el sábado 6 de junio acudió al homeópata de la localidad. Reportaba haberse sentido mejor con ese tratamiento, que todos los síntomas y molestias desaparecieron a excepción de «un dolor en la boca del estómago» que se le dispersaba por el vientre medio.

Durante las visitas se le realizaron mediciones de la glucosa plasmática posprandial, es decir, posterior a la ingesta de alimentos, y los resultados fueron siempre por arriba de $500 \mathrm{mg} / \mathrm{dl}$, alarmantemente elevados (véase gráfico 1), a pesar de lo cual en todo momento se negó a asistir a los servicios públicos de atención médica. Ello a su vez explica el deterioro corporal.

Gráfico 1: Glucometrías del 18/05 al 18/11 de 2009.

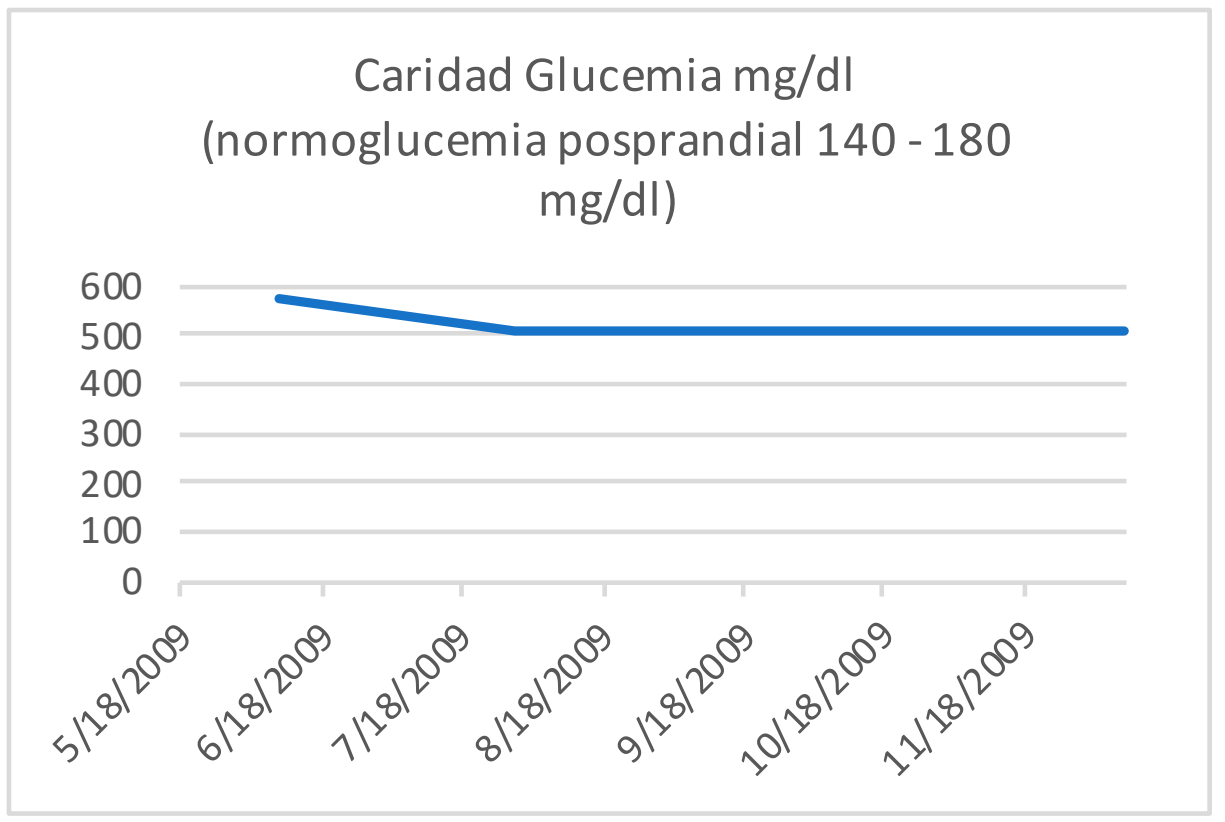

Fuente: Notas de campo.

En octubre de 2009, doña Caridad presentó una pequeña úlcera en un dedo del pie. A pesar de lavados que se le practicaron en casa, el daño evolucionó hacia la necrosis, y gradualmente se propagó a lo largo de la pierna.

El 7 de enero de 2010 se quejó de un agudo dolor en el pie y pidió que la llevaran al hospital donde el biomédico dictaminó que su estado era de avanzada gravedad: «su sangre está muy contaminada». Sugirió realizar la amputación de la pierna, sin garantizar la sobrevivencia de la enferma.

Decidieron no realizar la amputación. Doña Caridad falleció el 9 de enero de 2010. 


\section{Conclusiones}

Las pérdidas cíclicas, irreparables y catastróficas que sufrió doña Caridad: primero de su esposo y de sus cuatro hijos, y aún no se recuperaba de esa situación cuando sobrevino el arrasamiento de su aldea y con ello la desaparición forzada de sus padres y "posiblemente" de su hijo. Tales hechos configuran los elementos de memoria que prefiguran en gran medida los acontecimientos posteriores de su vida. Los recuerdos dieron forma, nutrieron y retroalimentaron el sufrimiento, la imaginación y el miedo, y en gran medida operaron como «pautas para la acción».

Respecto de la irrupción no tan sorpresiva de los kaibiles, destaca que doña Caridad y sus familiares, así como otros pobladores, no se paralizaron por el miedo. Parecían estar preparados. Lograron huir y refugiarse en un lugar preciso, bajo el resguardo de la guerrilla, tener acordados lugares de encuentro y haber preparado equipaje fuera del alcance del enemigo. Lo que me extraña es que dicha prevención no contemplara el aprovisionamiento para resistir las condiciones del ocultamiento y los días de travesía, que los llevó a padecer hambre al menos durante cinco días. Lo anterior no menoscaba el sufrimiento físico-emocional que de ello se derivó: «Tenía yo mucho espanto, mucho miedo, mucha hambre. Tal vez de ahí viene mi azúcar».

Otra de sus situaciones de reacción inmediata fue la que tuvieron en Huehuetenango, donde a pesar del agudo sufrimiento por la desaparición de sus padres e hijos, en vez de permanecer en la ciudad de manera pasiva y sin redes de apoyo, optaron por la única alternativa en dichas circunstancias: ocultarse y seguir huyendo.

En doña Caridad vemos cómo a partir de la tríada recuerdo-imaginar-miedo se configura una forma particular de estar en el mundo, en la que resaltan elementos de memoria ligados a eventos marcados por miedos previos. Los acontecimientos de Nebaj, aprendidos y luego desencadenados de manera semejante vuelven a representarse como posibilidades ante el levantamiento del EZLN en 1994. Asimismo, dicha tríada como un reflujo que la llevó a los lugares que alternativamente seleccionó para reencontrarse con su pasado. Dentro de este complejo destaca como motivo de esperanza, de acicate para continuar la vida, pero también como motor para los desplazamientos periódicos arriba mencionados, la ilusión de reencontrar al único hijo que quedó de su primer matrimonio. Ese aspecto que dio pie a un proceso intenso de 
imaginar posibilidades de reencuentro y le permitió paliar la desolación, la tristeza, la desesperación.

En su narrativa siempre hace mención de que los traslados a Guatemala y al sureste de México tenían como propósito, por un lado, reencontrar al hijo "perdido", toparlo en cualquier recodo; y por otro, reencontrarse con su pasado, literalmente revivir momentos, volver a los lugares, con familiares y gente. Recordar e imaginar, al imbricarse, funcionaron como motores que la impulsaron a tomar dichas decisiones. Por eso regresó a Guatemala en tres ocasiones: en 1992, luego, siete años después del exilio, y la última vez en 2009.

De estos eventos destaca la experiencia de imaginación vivida en uno de los regresos a Guatemala, relacionada con la estampa del "cántaro en el hombro» a partir de la cual incurrió en conductas que, en su parecer, le acarrearon un daño irreparable, y que menguaron en definitiva su condición física, emocional y su calidad de vida, sin que llegara a correlacionarlas con el desapego al tratamiento y el total caos con respecto a su atención médica.

La escena que se nos presenta cuando imagina al hijo es tan solo un ejemplo de un acontecer frecuente en la vida de doña Caridad. Evidencia el predominio en su narrativa de una mención constante: que "sueña" con reencontrarlo, y que ese anhelo pasa por encima de aspectos como el fallecimiento de su familia o el exterminio de su aldea.

El rejuego constante entre el recuerdo y el imaginar le generaba a doña Caridad constantes estados de estrés y, por consecuencia, estados anímico-vegetativos que gradualmente, aunados a la falta de apego al manejo de la diabetes, fueron incrementando el deterioro físico. Tales situaciones tuvieron mayor incidencia en los últimos años de su vida, hasta llegar al punto de mermar sus facultades y la capacidad para allegarse los recursos económicos a los que estaba acostumbrada cuando podía trabajar.

Ciertamente, la pérdida del esposo y de cuatro hijos por complicaciones del sarampión, y luego del único que le quedaba y de sus padres, a manos del ejército guatemalteco, constituyen acontecimientos no equiparables con cualquier otra tragedia. Aparecen como elementos constantes y predominantes en la memoria, difíciles de trasladar al inconsciente o como olvidos; recuerdos que resurgen de una o de otra manera en el día a día, que marcan y delimitan, a la par de los miedos latentes, el devenir cotidiano.

Por otro lado, ya antes señalé las ocasiones en que el miedo la impactó. Esa emoción le dejó una marca indeleble a partir de la cual se entretejieron derrote- 
ros en los que la mesura, la observación obsesiva y detallada del entorno, incluso la percepción delirante de la realidad determinó el curso de su vida.

La constante del miedo, entre otras cosas, llevó a doña Caridad a vivir ocultando su identidad, cambiando de nombre tanto en Guatemala como en México, así como a aprender y perfeccionar el español, no usar ropa que la identificara como guatemalteca ni como quiché, no solicitar asistencia o ayuda de cualquier tipo de autoridad civil, especialmente de migración, negarse a regularizar su situación legal aun cuando había concebido un hijo en México. Todo ello como práctica social de resguardo que la mayoría de los refugiados adoptan como medida de protección y que ella mantuvo hasta el fin de sus días.

Dicha previsión no era producto de una actitud paranoica: ilustra la agresiva política del gobierno mexicano en la frontera sur para controlar y restringir la deambulación libre de los refugiados y posteriormente evitar el flujo de migrantes hacia Estados Unidos. Esas prácticas que caían y caen en lo policiaco, aunque no las vivió en carne propia, las conoció por lo que sucedía a personas de sus redes del refugio.

El miedo a la deportación fue un factor importante para no acceder a los servicios públicos de atención médica, y para que acudiera en su lugar a la homeopatía, a la biomedicina privada y a otras alternativas terapéuticas, y que optara preferentemente por estas últimas debido a que la pobreza le impedía costear las consultas y los medicamentos, y así se creaba un círculo vicioso por la falta de control de la diabetes.

Las diferentes e innumerables causas de sufrimiento emocional en mujeres y hombres, especialmente en las primeras, constituye un factor importante en el desencadenamiento y deterioro humano, aspecto que desafortunadamente soslayan las políticas públicas nacionales en salud y atención.

\section{Referencias bibliográficas}

Acero, Cecilia, 2012, Viviendo con la enfermedad. Comparación de cómo viven la DM tipo 2 las personas que acuden al centro de salud "Los Pinos» en San Cristóbal de Las Casas, Chiapas, tesis de maestría inédita, México, Centro de Investigaciones y Estudios Superiores en Antropología Social-Sureste.

Acero, Cecilia, 2019, Representaciones en torno a la vivencia de la Diabetes Mellitus tipo 2 en los espacios domésticos en la ciudad de Tuxtla Gutiérrez, Chiapas, tesis de doctorado inédita, México, Facultad de Filosofía y Letras/Instituto de Investigaciones Antropológicas-Universidad Nacional Autónoma de México. 
Arganis Juárez, Elia N., 1998, Estrategias para la atención a la diabetes mellitus de enfermos residentes en Cosamaloapan, Veracruz, tesis de maestría inédita, México, Escuela Nacional de Antropología e Historia.

Arganis Juárez Elia N., 2005, «La autoatención en un grupo de ancianos con diabetes residentes en Iztapalapa D. F. », Cuicuilco, 12 (33), enero-abril, pp. 11-25.

Arias, Arturo, 1983, "Cultura popular, culturas indígenas, genocidio y etnocidio en Guatemala», Boletín de Antropología Americana, 7, julio, pp. 57-77.

Bakan, David, 1979, Enfermedad, dolor, sacrificio. Hacia una psicología del sufrimiento, México, Fondo de Cultura Económica.

Braunstein, Néstor A., 2008, Memoria y espanto o el recuerdo de la infancia, México, Siglo XXI Editores.

Bourdieu, Pierre, 2005, «Habitus, ethos, Hexis...», en Gilberto Giménez (comp.), Teoría y análisis de la cultura, México, Consejo Nacional para la Cultura y las Artes (Intersecciones).

Bustamante Danilo, Javiera, 2019, «Rompiendo el silencio. aportes desde la antropología chilena al campo de estudios de la memoria», Athenea Digital,19(2), julio, pp. 1-25.

Cardoso Gómez, Marco Antonio, 2006, «La cultura como configurador de estilos alimentarios antagónicos al tratamiento médico contra la diabetes. Cultura, dieta y diabetes», Cuicuilco, 13 (37), mayo-agosto, pp. 129-142.

Castoriadis, Cornelius, 1997, «El imaginario social instituyente», Zona Erógena, 35, en <http://www.ubiobio.cl/miweb/webfile/media/267/Castoriadis\%20Cornelius\%20 -\%20El\%20lmaginario\%20Social\%20Instituyente.pdf > (consulta: 14/05/16).

Comandancia General EZLN, 1994, «Primera declaración de la Selva Lacandona», en Enlace Zapatista, en <https://enlacezapatista.ezln.org.mx/1994/01/01/primera-declaracion-de-la-selva-lacandona/> (consulta: 03/09/19).

Corbin, Juan Armando, s./f, «Sufrimiento emocional: 9 claves para detectarlo y superarlo Varias razones pueden llevar a este estado emocional negativo. ¿Hay formas de salir de él?», Psicología Mente, en <https://psicologiaymente.com/clinica/sufrimiento-emocional> (consulta 22/07/19).

Csordas, Thomas J., 1993, "Somatic Modes of Attention», Cultural Anthropology, 8 (2), mayo, pp. 135-156.

Das, Veena, Arthur Kleinman, Margaret Lock, Mamphela Ramphele y Pamela Reynolds, (eds.), 2001, Remaking a world. Violence, social suffering and recovery, California, University of California Press.

Diccionario de la Real Academia Española (DRAE), s./f, Diccionario de la lengua española, <https://dle.rae.es/?id=PDGS53g> (consulta: 9/04/19).

Domínguez Mos, A., 2017, «Los cuidados de la salud en personas que viven con diabetes: enfoque etnográfico antropológico y perspectiva de género», Salud Colectiva, 13 (3), pp. 375-390.

Eroza, Enrique, 2014, «La obesidad y el sobrepeso: sus múltiples paradojas entre los mayas de los Altos de Chiapas», en Jaime Page (coord.), Enfermedades del rezago y emergentes desde las ciencias sociales y la salud pública, México, Programa de Investigaciones Multidisciplinarias sobre Mesoamérica y el Sureste-UNAM. 
Eroza, Enrique, 2017, El cuerpo como texto y eje vivencial del dolor: las narrativas del padecimiento entre los Chamulas, México, CIESAS.

Farmer, Paul, 2004, "On Suffering and Structural Violence: A View from Below», en Nancy Scheper-Hughes, Philippe Bourgois (eds.), Violence in War and Peace. An Anthology, UK, Blackwell, pp. 281-289.

Good-Eshelman, Catharine Louise, 2015, «Las cosmovisiones, la historia y la tradición intelectual en Mesoamérica», en Alejandra Gámez y Alfredo López-Austin (coords.), Cosmovisión mesoamericana. Reflexiones, polémicas y etnografías, México, El Colegio de México/FCE/Benemérita Universidad Autónoma de Puebla.

Hunt, Linda M., Miguel A. Valenzuela y Jacqueline A. Pugh, 1998, «¿Por qué me tocó a mí? Mexican American diabetes mellitus patients' causal stories and their relationship to treatment behaviors», Social Science and Medicine, 46 (8), pp. 959-969.

Jodelet, Denise, 2008, «El movimiento de retorno al sujeto y el enfoque de las representaciones sociales», Cultura y representaciones sociales. Un espacio para el diálogo transdisciplinario, 3 (5), septiembre, pp. 32-63.

Kleinman, Arthur, 1988, The illness narratives: Suffering, healing and the human condition, USA, Perseus Books Group.

Kleinman, Arthur, 1998, «Experience and Its Moral Modes: Culture, Human Conditions, and Disorder», en Grethe B. Peterson (ed.), The Tanner Lectures on Human Values, vol. 20, Salt Lake City, University of Utah Press, pp. 357-420.

Kleinman, Arthur y Joan Kleinman, 1991, "Suffering and its professional transformation: Toward an ethnography of interpersonal experience», Culture, Medicine and Psychiatry, 15 (3), Septiembre, pp 275-275.

Kobrak, Paul, 2003, Huehuetenango: historia de una guerra, Guatemala, Centro de Estudios y Documentación de la Frontera Occidental de Guatemala (CEDFOG).

Le Breton, David, 1999, Las pasiones ordinarias. Antropología de las emociones, Buenos Aires, Ediciones Nueva Visión.

Le Breton, David, 2012, "Por una antropología de las emociones», Revista Latinoamericana de Estudios de sobre Cuerpos, Emociones y Sociedad, 10 (4), diciembre-marzo, pp. 69-79.

Lerin Piñón, Sergio, Clara Juárez y Diana Reartes, 2015, "Creencias de indígenas chiapanecos en torno a la diabetes y posibilidades de atención intercultural», Salud Problema, segunda época, 9 (17), enero-junio, pp. 27-41.

Lerin Piñón, Sergio, 2017, «Recursos institucionales para diabéticos maya hablantes de Tizimín (Yucatán). Carencias y logros en los Grupos de Ayuda Mutua (GAM)», Revista Pueblos y fronteras digital,12(23), junio-noviembre, pp. 77-98.

Lutz, Catherine A., 1998, Unnatural Emotions. Everyday sentiments on a Micronesian Atoll. Their challenge to western Theory, Chicago, The University of Chicago Press.

Mayo Clinic, 2019, Trastorno de Estrés Postraumático (TEPT), en <https://www.mayoclinic.org/es-es/diseases-conditions/post-traumatic-stress-disorder/symptoms-causes/syc-20355967> (consulta: 29/04/19).

Mercado Martínez, Francisco, 1996, Entre el infierno y la gloria: La experiencia de la enfermedad crónica en un barrio urbano, México, Universidad de Guadalajara. 
Mercado Martínez, Francisco J. e Igor M. Ramos-Herrera, 2002, «Diabetes: the layperson's theories of causality», Qualitative Health Research, 12 (6), pp. 792-806.

Mercado Martínez, Francisco J., Leticia Robles-Silva, Igor M. Ramos-Herrera, Nora MorenoLeal y Elizabeth Alcántara Hernández, 1999, «La perspectiva de los sujetos enfermos. Reflexiones sobre pasado, presente y futuro de la experiencia del padecimiento crónico», Cad. Saúde Pública, 15 (1), pp. 179-186.

Montesi, Laura, 2014, «Beyond race and ethnicity: How an ethnography of diabetes mellitus can contribute to a socially complex approach to hyperglycemia, human suffering, and care», Society, Biology \& Human Affairs, 78 (1\&2).

Montesi, Laura, 2017a, «La diabetes como metáfora de vulnerabilidad. El caso de los ikojts de Oaxaca», Revista Pueblos y Fronteras digital, 12(23), junio-noviembre, en <http:// www.pueblosyfronteras.unam.mx/index.php/index.php/pyf/article/view/287>.

Montesi, Laura, 2017b, «Ambivalent food experiences: Healthy eating and food changes in the lives of Ikojts with diabetes mellitus», International Review of Social Research, 7(2), pp. 99-108.

Montesi, Laura, 2018, "Como Si Nada": Enduring Violence and Diabetes among Rural Women in Southern Mexico», Medical Anthropology, 37 (3), pp. 206-220.

Moreno Altamirano, Laura, 2006, El drama social de las personas con diabetes mellitus, tesis de doctorado inédita, México, ENAH.

Nazar-Beutelspacher, Austreberta y Benito Salvatierra Izaba, 2010, «Envejecimiento, calidad de vida y mortalidad temprana en hombres diabéticos. Una aproximación desde la perspectiva de género», Papeles de Población, 16 (64), abril-junio, pp. 67-92.

Nazar-Beutelspacher Austreberta y Emma Zapata Martelo, 2012, "Género, pobreza y salud mental», Ecofronteras, 15, abril-julio, pp. 14-17.

Page, Jaime, Enrique Eroza y Cecilia Acero, 2018, Vivir sufriendo de azúcar: representaciones sociales sobre la diabetes mellitus en tres localidades de los Altos de Chiapas, Centro de Investigaciones Multidisciplinarias sobre Chiapas y la Frontera Sur-UNAM

Pérez, Guillermo, s./f, Noradrenalina, en <www.norepinefrina.com> (consulta: 03/04/19).

Rock Melanie, 2003, «Sweet blood and social suffering: rethinking cause effect relationships in diabetes mellitus distress and duress», Medical Anthropology, 22 (2), pp. 131-174.

Rosaldo, Michelle Z., 1984, "Toward an anthropology of self and feeling», en Richard A. Shweder y Robert A. Le Vine (eds.), Culture theory. Essays on Mind, Self, and Emotion. London. Cambridge University Press.

Salazar Fraile, José y Ermengol Sempere, 2012, Malestar emocional: Manual práctico para una respuesta en atención primaria, Valencia, Generalitat, Conselleria de Sanitat Ed.

Sirito, Silvia Viel, Dolors Mateo Ortega, Cruz Sánchez Julve, Adrián Chaurand Morales y Melinda González Concepción, 2014, Guía de detección del malestar emocional en la atención paliativa integral, Barcelona, Societat Catalanobalear de Cures Palliatives.

Thomas Téllez, Eduardo, 2019, «Trastornos de ansiedad: La marca del miedo», ¿Cómo ves?, 21 (250), pp. 8-16. 
Trujillo Olivera, Laura Elena, Austreberta Nazar Beutelspacher, Emma Zapata Martelo y Erin I. J. Estrada Lugo, 2008, «Grupos domésticos pobres, diabetes y género: renovarse o morir», Papeles de Población, 14 (58), octubre-diciembre, pp. 231-258.

Wolman, Benjamín B., 1984, Diccionario de las ciencias de la conducta, México, Ed. Trillas. Yáñez Moreno, Pedro, 2012, He hipi cöhimoqueepe hac hocoaa ha, ¿zooh sah pacta teeh? 'Sé que estoy enfermo, ¿y qué hacer?': la diabetes mellitus y sus significados entre los comcaac de Socaaix (Punta Chueca), Sonora, tesis de maestría inédita, México, El Colegio de Sonora.

Yáñez Moreno, Pedro, 2016, La pena muda: Sufrimiento en cuidadores de familiares con diabetes mellitus tipo 2 y amputación, en Guadalajara, Jalisco, tesis de doctorado inédita, México, CIESAS-Occidente.

\section{Cómo citar este artículo:}

Page Pliego, Jaime Tomás, 2019, «Memoria, imaginación y miedo en la génesis de la diabetes mellitus. El caso de una mujer guatemalteca», Revista Pueblos y fronteras digital, volumen 14, e-433. https://doi. org/10.22201/cimsur.18704115e.2019.v14.433 